\title{
Smart system for water level and flow measurement and control in open canals
}

\author{
Rustam Baratov", Yakub Chulliyev, and Sodiq Ruziyev \\ Tashkent Institute of Irrigation and Agricultural Mechanization Engineers Tashkent, Uzbekistan
}

\begin{abstract}
Nowadays, water and energy resources are becoming scarcer due to the inefficient use of these vital resources in agricultural irrigation worldwide. The unique solution to this problem is the application of smart technology in water distribution systems. But the most pivot weir installations in water distribution systems have not access to power and have a remote location from the power line. This problem requires developing a low-power smart system for water level and flow measurement and control in open canals. In this study, the authors attempt to detect the advantages and disadvantages of existing methods and hardware, the most important influencing factors of the system for energy efficiency, and develop a more energy-efficient and precise smart system for water flow and level measurement and controls in open canals. The question of the development of a low power smart system for water flow and level measurement and control in open canals in terms of energy efficiency is considered as well. Theoretical and experimental research results are submitted.
\end{abstract}

\section{Introduction}

Water is a strategic resource of any country. But water and energy resources are becoming scarcer as people exploit these vital resources aggressively. If the water consumption from 1950 to 1990 increased by 2-2.5 times and amounted to 300 cubic kilometers, the amount of water consumed exceeds 500 cubic kilometers in the world [1].

There are no substitutes for water, and its scarcity causes serious Economic, Social and Demographic problems in the country. Recently in many regions of the world, particularly in Central Asia, Africa, the Near East, the Southwest U.S, and some states of Latin America, faces the challenge of irrigation and drinking water shortages.

There is one of the largest irrigation systems in the world, providing water about 7.95 million hectares of land under irrigation in Central Asia. Big dams, water reservoirs, canals, pumping stations, and drainage systems were constructed in the region.

Agriculture uses $85 \%$ of available freshwater resources worldwide for cultivating the plants using traditional irrigation methods, and it increases the demand for the water resources in day-to-day life as the population grows [1,2]. Approximately $90 \%$ of water resources are used for agricultural irrigation purposes in the Central Asian region [3, 4].

\footnotetext{
*Corresponding author: rbaratov@mail.ru
} 
According to last statistical information, the region loses 1.7 billion US dollars (or $3 \%$ of GDP) annually because of inefficient use of energy resources. Due to water and energy scarcity, annual reduction of agricultural manufacture has estimated up to 2 billion US dollars [3].

Hence agricultural irrigation, as the biggest water and energy consumer, requires advanced water and energy-saving technology. So, in front of the scientists stands the big issue of the day as follows:

1. develop a new approach to effective water resources management;

2. application of low power water flow measurement and control hardware;

3. automation of water distribution systems based on smart sensors technology, and creation of water monitoring system.

4. in this study, the authors attempt to develop a more energy-efficient and precise smart system for water flow and level measurement and control in open canals.

5. the literature reviews show that most existing measurement and control systems require a power source from a power line $[5,6]$.

6. for example, the device for water flow measurement and control in open canals was developed [6-13]. The disadvantage of this device is the low accuracy due to the impossibility of separating electromotive force (EMF) amplitude variation when changing the velocity of the water flow and the gap between the electrodes and the complicated design.

7. a smart sensor for automatic drip irrigation systems for paddy cultivation was proposed in [2]. But, the system has no water flow measurement and control in open canals features.

8. in addition, an automatic pivot weir control system was proposed in [16]. The system has two ultrasonic sensors to measure water depth upstream and downstream of the weir, and the data will be transferred to a computer for further processing. However, irrigation water is usually turbid and has small particles, stones, and other things. In this case, ultrasonic sensors often generate false signals and have not high accuracy.

Nowadays all electrically operated modern flow measurement and water level control system has actuators that provide a method of raising or lowering canal gates. A significant amount of electrical energy is used for actuators of the gate controlling system during irrigation season. However, it must be borne in mind that the existing water distribution devices or gates have dispersed locations, and power sources from the power line are needed. It is an economically unprofitable and expensive thing to supply electricity from the power line to each water distribution gate.

These all problems mentioned above require the development of a low-power smart system for water level and flow measurement and control in open canals. Usually, there are two types of actuators that are considered as energy consumption elements in irrigation systems:

1. a threaded stem or screw jack attached directly to the gate;

2. reduction gear mechanisms (including chain-driven sprockets) control the gate's speed and provide a mechanical advantage to overcome the forces involved in lifting the gates.

The main source of the drive mechanism of the gates is an electrical motor. Several factors can dictate the power or energy consumption of the motor. A heaver gate, a gate operating with a big difference in water levels across the gate, a fast-moving gate requires more power and more energy consumption.

Hence the authors pay their attention to the development of low power and more precise smart system for water flow and level measurement and controls in open canals. The study of the existing problem is presented in Section I, the Section II describes materials and 
methods, working principles of the proposed system, and Section III covers experimental results, and Section IV discusses the future study and conclusion.

\section{Materials and methods}

Various types of water flow measurement and level control system for open canals have been developed now [1-15]. The most commonly used in open water distribution canals is rectangular vertical lift slide gate [6-10], [14-16]. But, the growing interest in energyefficient and more precise smart control systems requires an advanced method, which allows a significantly decrease wastage of water and energy resources. The vertical opening slide gate is mechanically simpler and well suited for general use and easy to install and service in the field. However, we can itemize the following drawbacks of this design based on research investigations;

1. power consumption of the actuators is increased due to the weight of the gate;

2. some mechanical influence as corrosion and binding of teeth of the gears or other mechanical parts will create additional loads to the gate and electric motor's driving mechanism.

The authors investigated the pivot weir or overshot gate in terms of energy efficiency. The pivot weir operates in submerged in water condition, and flow measurement realizes based on an equation relating to the water level and pivot weir opening angle $(\alpha)$ (see figure 1 below) $[6,8,9,10,13,14,16]$.

The pivot weir consists of a rectangular panel that is hinged to the bottom of the canal. Two cables connected the top of the panel to the drive mechanism and can then be used to raise and lower the gate to control the upstream and downstream water levels and flow in open canals $[5,6,8,9,13,14,16]$.

The pivot weir or gate controlling system works under several forces. The most significant influencing component to the energy consumption of the gate is the hydrostatic pressure force against the gate and the weight of the water above the pivot weir or overshot gates.

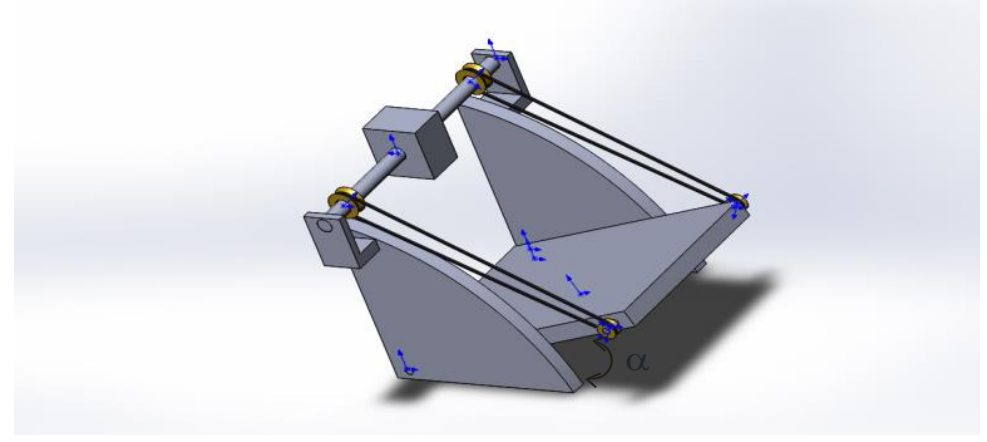

Fig. 1. General view of the pivot weir

Therefore, we have investigated the hydrostatic pressure force acting to the pivot weir by comparison with the vertical opening slide gate and get the following equation:

$$
\mathrm{F}_{\text {overall,cl }}=\mathrm{k}\left(\mathrm{f} \cdot \mathrm{F}_{\mathrm{R}, \mathrm{cl}} \pm \mathrm{W}\right)=\mathrm{k}\left[\begin{array}{l}
\mathrm{f} \cdot \rho \cdot \mathrm{g} \cdot \mathrm{w}\left(\left(\mathrm{H}_{\text {up.min }}+\left(\Delta \mathrm{H}-\frac{\mathrm{H}}{2}\right) \cdot \sin \alpha\right) \cdot \mathrm{H}-\right. \\
\left.-\frac{1}{2}\left(\mathrm{~h}_{\text {down.max }} \cdot \cos \alpha\right)^{2}\right)+\mathrm{W} \cdot \cos \alpha
\end{array}\right]
$$


where $\mathrm{H}$ is water level or height of the gate $(\mathrm{m}), \mathrm{H}_{\text {up }}, \mathrm{H}_{\text {up.min }}$ is upstream head (water level) and its minimum value, $\Delta \mathrm{H}$ are differences between upstream water head and its minimum value, $\mathrm{h}_{\text {down.max }}$ are downstream head (water level) and its maximum value, $\mathrm{w}$ is width of the gate $(\mathrm{m}), \mathrm{k}$ is reserve factor, $\mathrm{W}$ is weight of the gate $(\mathrm{N}), \mathrm{f}$ is friction coefficient (dimensionless),

or at the gate opening process:

$$
\mathrm{F}_{\text {overall,op }}=\mathrm{k} \cdot\left[\begin{array}{l}
-\mathrm{f} \cdot \rho \cdot \mathrm{g} \cdot \mathrm{w}\left(\left(\mathrm{H}_{\text {up.min }}+\left(\Delta \mathrm{H}-\frac{\mathrm{H}}{2}\right) \cdot \sin \alpha\right) \cdot \mathrm{H}-\right. \\
\left.-\frac{1}{2}\left(\mathrm{~h}_{\text {down.max }} \cdot \cos \alpha\right)^{2}\right)-\mathrm{W} \cdot \cos \alpha
\end{array}\right]
$$

These obtained equations (1) and (2) will be used in the future to determine the consumed power by the actuators of the horizontal opening overshot gate.

In the first stage, we have developed a block diagram for water level and flow measurement and control in open canals (see figure 2).

The proposed water level and flow measurement and control system based on smart sensor consists of Atmega 2560 microcontroller, stepper motor control unit, LCD, and pivot weir is shown in figure 2 below.

The gate angle of the pivot weir will be converted to the voltage Ue by driving element (DE), and signals further transmit to the comparison element. The signal Uel from the smart sensor (SS) through the measuring loop (ML) and feedback canal also transfers to the comparison element, where two signals are compared. If there is a difference between the existing and the established signals, the zero indicator will show the intensity of the difference, indicating the direction and value of the signal. The voltage difference $\Delta \mathrm{Ue}$ transfers to the Controller (cont), and the stepper motor starts moving gates in corresponding directions.

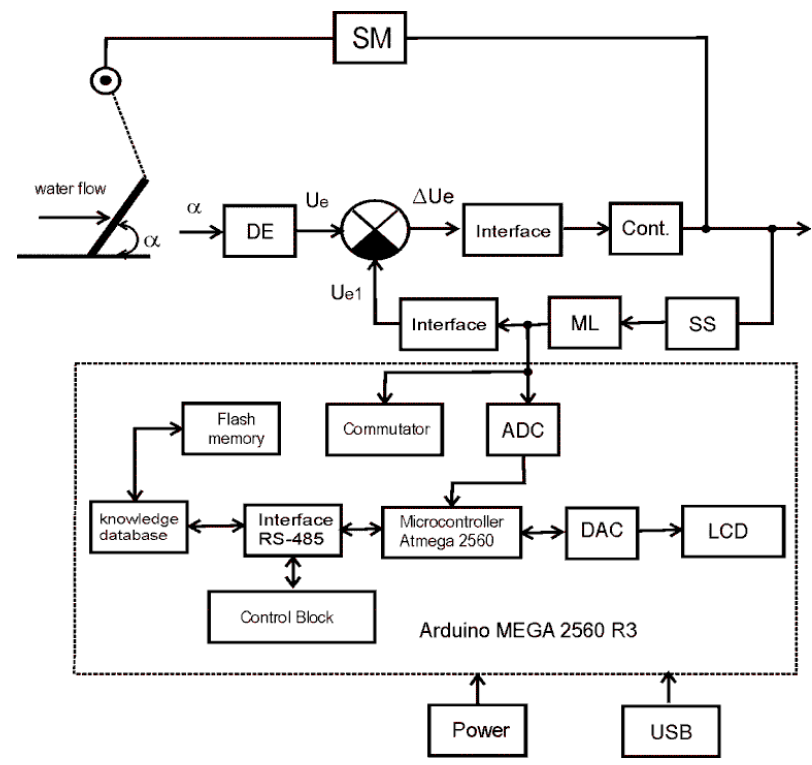

Fig. 2. Block diagram of the smart sensor-based water level and flow measurement and control system 
In (9) and (10), it is shown that the hydrostatic pressure forces acting on the flat surfaces of the pivot weir are much less than the vertical opening slide gate. It means that there is a possibility to improve the energy consumption of the gate by optimizing some controlling processes.

All considerations mentioned above require research investigation and optimization of gate operations. Now we can estimate the total energy consumption of the electric motor based on an equation related to the lifting motor power:

$$
\begin{aligned}
P=\frac{\mathrm{F}_{\text {overall..dose }} \cdot \mathrm{v}}{\eta} & =\mathrm{k}\left(\mathrm{f} \cdot \mathrm{F}_{\text {overal.close }}^{\prime}+\mathrm{W}\right) \cdot \mathrm{v} / \eta=\left[\mathrm { k } \cdot \mathrm { f } \cdot \rho \cdot \mathrm { g } \cdot \mathrm { w } \left(\left(\mathrm{H}_{\text {up.min }}+\left(\Delta \mathrm{H}-\frac{\mathrm{H}}{2}\right) \cdot \sin \alpha\right) \cdot \mathrm{H}-\right.\right. \\
& \left.\left.-\frac{1}{2}\left(\mathrm{~h}_{\text {down.max }} \cdot \cos \alpha\right)^{2}\right)+\mathrm{W} \cdot \cos \alpha\right] \cdot \mathrm{v} / \eta
\end{aligned}
$$

where $F_{\text {overall }}$ is overall force acting on the gate, $\eta$ is efficiency factor of lifting gates, $\mathrm{v}$ is lifting speed $(\mathrm{m} / \mathrm{s})$.

In equation (3) usually gate lifting speed is $\mathrm{v}=0.25-0.3 \mathrm{~m} / \mathrm{min}$, and the efficiency factor of the lifting mechanism depends on what type of mechanism we are using. For example, if we use a screw jack lifting mechanism efficiency factor is $\eta=0.63-0.85$ The pivot weir has about 1.8 and 2 times less power consumption than the vertical opening slide gate. This advantage of the horizontal overshot gate keeps to point the develop off-line power sources for the smart system of water level and flow measurement and control gates[17,19,20]. We plot the power consumption of the gate lifting actuators versus moving coordinate following the obtained formula (3). See figure 3 below.

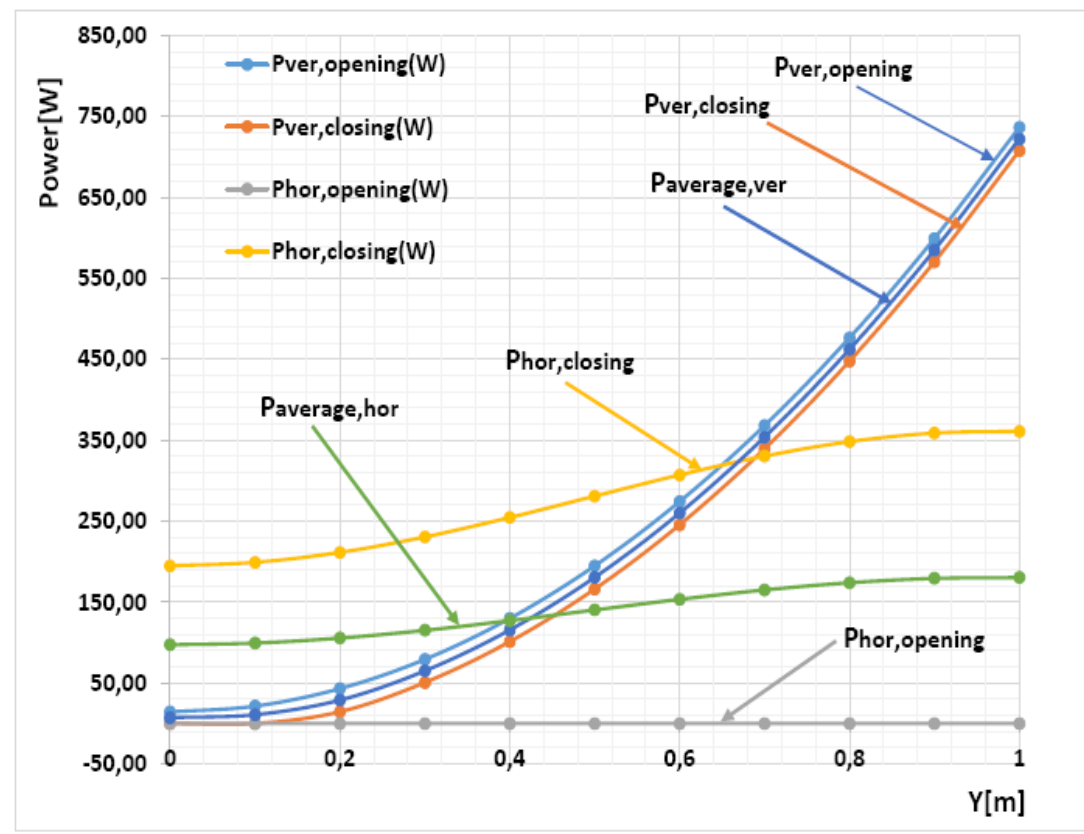

Fig. 3. Energy consumption of the vertical opening slide and horizontal opening overshot gates and its average values. 


\section{Results and Discussion}

The smart system for water level and flow measurement and control has been developed [18] (see figure 4). Experiments were conducted in the Laboratory of Electrical Engineering and Mechatronics Department of TIIAME. In experiments, we have used PIC 18F4620-I/PND microcontroller, operational amplifier MCP602-I/P-ND, stepper motor WSM-237, and NPN transistors ZTX-1055A, and other electronic components (figure 4).
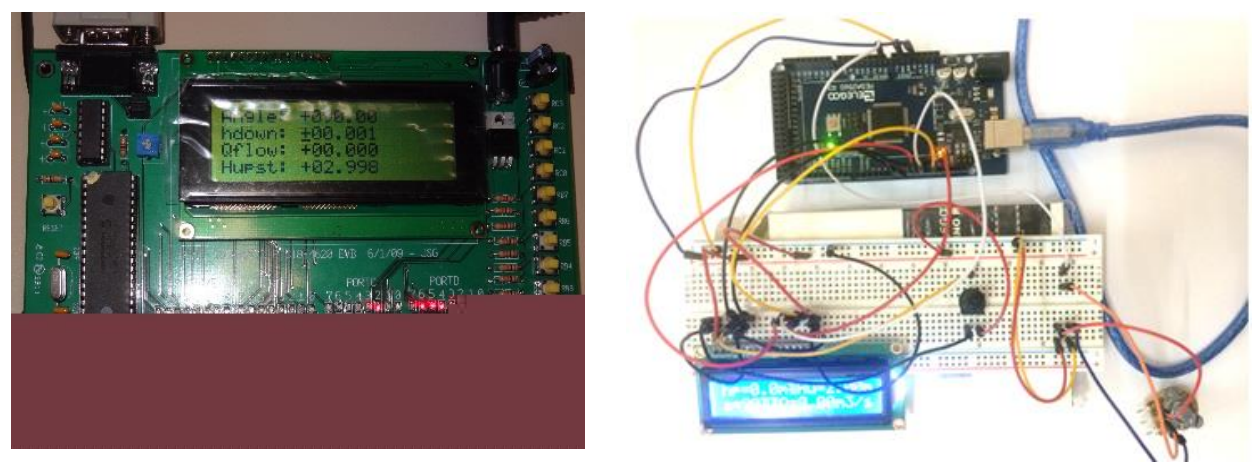

Fig. 4. Developed smart system for water flow measurement and level controls in open canals

In results were obtained curves of water flow $Q$, upstream and downstream water levels in open canals. Figure 5 shows variations of water flow, upstream and downstream water levels depend on the angles of the gate.

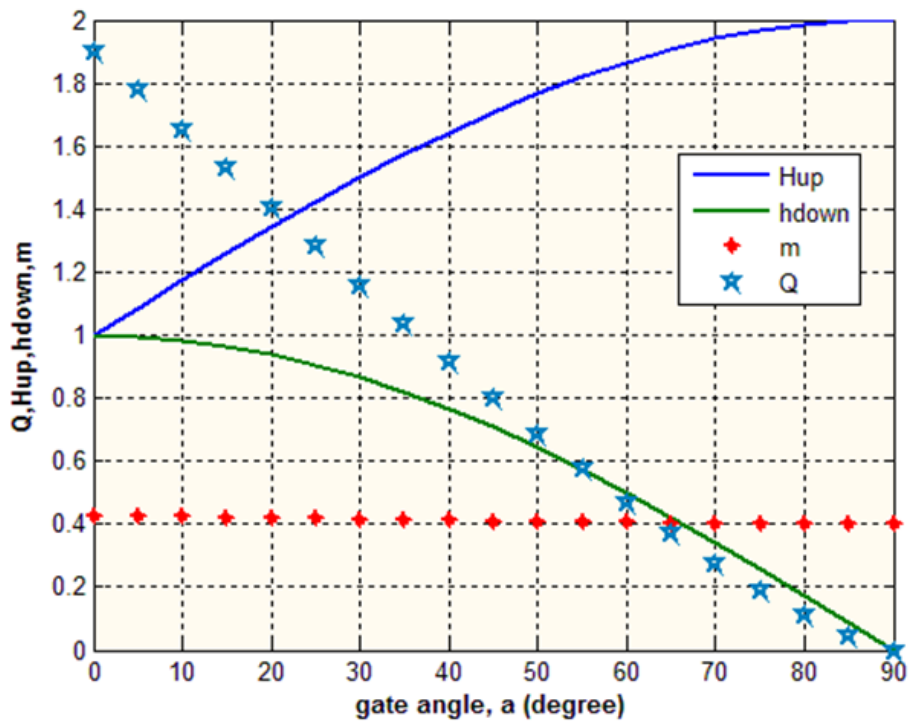

Fig. 5. Variations of water flow, upstream and downstream water levels in open canals

The experimental curve is close to a theoretical result. We use the least-squares method for statistical analysis. We have used the extreme method of approximating a nonlinear flow 
characteristic by a polynomial. The resulting solution of a 5th-degree polynomial satisfies the requirements. As a result, the resulting expression is as follows:

$$
Q=-2 \cdot 10^{-9} \cdot \alpha^{5}+4 \cdot 10^{-7} \cdot \alpha^{4}-3 \cdot 10^{-5} \cdot \alpha^{3}+0,0005 \cdot \alpha^{2}-0,0031 \cdot \alpha+1,7977
$$

In this expression, the corresponding value of $\mathrm{R}^{2}$ is very close to 1 , that is $\mathrm{R}^{2}=0.9994$. This is good fitting to the data and completely satisfies the requirements mentioned above.

\section{Discussion and conclusion}

This research study has not concluded yet, but we have preliminary theoretical and experimental outcomes. The following research investigations should be done in the future:

1. experimental validation;

2. dynamics study: influence of flow disturbance for flow measurement;

3. develop an off-line power source;

The pivot weir has a simple design in terms of flow measurement and level control in open canals; power consumption is about two times less than the vertical opening slide gate. There is a possibility of accurate flow measurement and water level controls in a wide range of water flow, easy automation, have the ability of the pivot weir to handle flow surge with limited depth changes.

Above mentioned advantages increase the overall efficiency of water distribution systems, promote precision water flow control, save significant amounts of water, decrease inefficient water distribution that promotes water waste on a large scale, promote reliable monitoring of used energy and water recourses.

\section{References}

1. Baratov R.J., Djalilov A.U., Chulliyev Y.E. Low Power Smart System Development for Water Flow Measurement and Level Controls in Open Canals, 6(12), (2019)

2. Barkunan S.R., Bhanumathi V., Sethuram J. Smart sensor for drip irrigation systems for paddy cultivation. Computers and Electrical Engineering journal, 73, pp. 180-193, (2019)

3. UNDP Homepage, http://www.undp.uz/en/publications/?\&page=24. (2007)

4. Jury W A, Vaux H J. The emerging global water crisis: managing scarcity and conflict between water users. Adv.Agron 95, pp.1-75 (2007)

5. Seyyed Mojtaba Azimfar, Seyyed Abbas Hosseini, Amir Khosrojerrdi. Derivation of discharge coefficient of a pivot weir under free and submergence flow conditions. Flow Measurement and Instrumentation 59, pp.45-51, (2018)

6. RUBICON Homepage. http://www.rubicon.com.au/EN/products/slipmeter.html.

7. Hager W.H. Design Procedure for Flow Over Side Weirs, ASCE, vol. 117 (1). 1(991).

8. Filippov E. Hydraulics of hydrometric structures for open flows. Gidrometeoizdat, Leningrad (in Russian), (1990)

9. John A.Roberson and Clayton T. Crowe. Engineering Fluid Mechanics. Houghton Mifflin Company, Boston, Dallas, Geneva, Illinois, Lawrenceville, New Jersey, Palo Alto. (1985)

10. BLUMBERG, A,F., Galperin B and O'Connor D J. Modeling Vertical Structure of Open- Channel Flows, Journal of Hydraulic Engineering, ASCE vol. 118, 8, pp.11191134. (1992).CSÉPAI L and Kastanek, F. Flow Regulation by Automatically Controlled Overflow Weirs, Water Resources, vol. 26, 5, pp.625-628. (1992) 
11. Bijankhan M, Ferro V. Experimental Modeling of Submerged Pivot Weir. Irrigation and Drainage Engineering, p.146 (3). (2020)

12. Wahlin B T and Replogle J A. Flow Measurement Using an Overshot Gate. United States Department of the Interior Bureau of Reclamation 111, pp.298-102. (1994)

13. Baratov R J, Djalilov A U, Chulliyev Y E. Embedded system for gate controlling and flow measurement in open canals. K. Bonfig (Germany). Seventh World Conference on Intelligent Systems for Industrial Automation, WCIS, B-Quadrat Verlog. pp.214 220. Tashkent, (2012)

14. Radjabov A, Amirov S, Baratov R J, Shoyimov Y. The Device for measurement and regulation of water flow. Patent of Republic of Uzbekistan N2834 (UZ), G 01 F 1/58. B.I. N3. (1995)

15. Mohammed Javad Monem and Zeinab Hosseinzade. Construction and Evaluation of Automatic pivot weir control system. $21^{\text {st }}$ International Congress on Irrigation and Drainage, ICID, Tehran, pp.7-21. (2011)

16. Denmuhammadiev A M, Shoyusupov Sh A, Chulliev Ya E. Low-power solar stations on dam surfaces of reserrvoirs. International Scientific and Technical Conference "Construction Mechanics, Hydraulics and Waer Resources Engineering", Mechanization, electrification of agriculture and renewable energy, Tashkent, Uzbekistan. (2020)

17. Baratov R J, Djalilov A U. The questions of development of smart sensors for control objects of hydro melioration systems. Proceedings of the Second World Conference on Problems of receiving, processing and transfer of information, September 19 - 20, Ufa State Aviation Technical University, UFA, Russia, pp.224-228 (in Russian). (2019)

18. Bolotin O., Portnoy G., Razumovsky K. Primary sensors for energy enterprises. Energy security and energy saving 5, pp.28 - 32, (2012)

19. Bolotin O, Portnoy G., Razumovsky K Modern sensors for measuring current and voltage. ISUP 1 (61), pp.18 - 25. (2016) 